\title{
Porous Carrageenan-Derived Carbons for Efficient Ciprofloxacin Removal from Water
}

\author{
João Nogueira ${ }^{1}\left(\mathbb{D}\right.$, Maria António $^{1}$, Sergey M. Mikhalev ${ }^{2}$, Sara Fateixa ${ }^{1}\left(\mathbb{D}\right.$, Tito Trindade ${ }^{1}(\mathbb{D}$ and \\ Ana L. Daniel-da-Silva ${ }^{1, * \mathbb{D}}$ \\ 1 CICECO-Aveiro Institute of Materials, Department of Chemistry, University of Aveiro, 3810-193 Aveiro, \\ Portugal; jh.nogueira@ua.pt (J.N.); maantonio@ua.pt (M.A.); sarafateixa@ua.pt (S.F.); tito@ua.pt (T.T.) \\ 2 Centre for Mechanical Technology and Automation - Nanotechnology Research Group (TEMA-NRD), \\ Mechanical Engineering Department, Aveiro Institute of Nanotechnology (AIN), University of Aveiro, \\ 3810-193 Aveiro, Portugal; mikhalev@ua.pt \\ * Correspondence: ana.luisa@ua.pt; Tel.: +351-234-370-368
}

Received: 21 November 2018; Accepted: 3 December 2018; Published: 4 December 2018

\begin{abstract}
Porous carbon materials derived from biopolymers are attractive sorbents for the removal of emerging pollutants from water, due to their high specific surface area, high porosity, tunable surface chemistry, and reasonable cost. However, carrageenan biopolymers were scarcely investigated as a carbon source to prepare porous carbon materials. Herein, hydrochars (HCs) and porous activated carbons (ACs) derived from natural occurring polysaccharides with variable sulfate content $(\mathrm{K}-, \mathrm{l}$ - and $\lambda$-carrageenan) were prepared and investigated in the uptake of ciprofloxacin, which is an antibiotic detected in water sources and that poses serious hazards to public health. The materials were prepared using hydrothermal carbonization and subsequent chemical activation with $\mathrm{KOH}$ to increase the available surface area. The activated carbons were markedly microporous, presenting high specific surface area, up to $2800 \mathrm{~m}^{2} / \mathrm{g}$. Activated carbons derived from $\mathrm{k}$ - and $\lambda$-carrageenan showed high adsorption capacity (422 and $459 \mathrm{mg} / \mathrm{g}$, respectively) for ciprofloxacin and fast adsorption kinetics, reaching the sorption equilibrium in approximately $5 \mathrm{~min}$. These features place the ACs investigated here among the best systems reported in the literature for the removal of ciprofloxacin from water.
\end{abstract}

Keywords: carrageenan; hydrochar; activated carbon; adsorption; ciprofloxacin

\section{Introduction}

Emerging pollutants are a vast series of man-made chemicals such as cosmetics, pesticides and pharmaceuticals that are essential to modern society and whose production has increased dramatically over the last century. The continuous and uncontrolled discharge of such substances into the environment, from distinct pollution sources, contributes to their accumulation in the aquatic compartments, with potentially harmful effects $[1,2]$. Effects on human health, environment and aquatic ecosystems are still poorly studied, but may include endocrinal disruption, promotion of antibiotic resistance, and chronic toxicity [3,4]. Unfortunately, wastewater treatment plants (WWTP) are currently unable to completely remove most of these compounds [5,6]. This is the case of ciprofloxacin (CIP, Scheme 1), an antibiotic that belongs to the class of quinolones and is used to treat several bacterial infections in animals and humans [7]. Ciprofloxacin can be found in wastewater, due to improper disposal and incomplete metabolization of the drug in humans. The average CIP removal rate in WWTPs is about $60 \%$ [5], resulting in wastewater effluents with concentrations that can still exceed $1 \mu \mathrm{g} / \mathrm{L}$ [8]. Furthermore, the detected amount of CIP in wastewaters discharged from hospitals and drug production units is much higher, up to $150 \mu \mathrm{g} / \mathrm{L}$ and $30 \mathrm{mg} / \mathrm{L}$, respectively, which is potentially harmful to human health and ecosystems [9-11]. A recent study has indicated ciprofloxacin as the 
most widespread antibiotic in sea water in the Antarctic [12]. The presence of CIP in water sources poses serious hazards to public health also because it can promote antimicrobial resistance in certain pathogenic microorganisms [12-14].

Given the limitations of conventional treatments implemented in WWTPs, new, sustainable and effective technologies are sorely needed. Several methods have been proposed for the removal and degradation of CIP from water, including advanced oxidation processes [15], photocatalytic treatment [16], electrocoagulation [9], biodegradation [17] and adsorption [18,19]. Among these methods, adsorption is an interesting process in view of its simplicity of implementation, low cost, high efficiency, and less production of toxic intermediates. In order to achieve high performance adsorptive separation, it is crucial to select sorbent materials with high capacity, chemical selectivity and fast rate of adsorption. This quest has boosted the development of new types of efficient sorbent materials. A variety of carbon-based materials have been investigated as sorbents for the uptake of CIP [20-23]. Among these materials, porous carbon such as activated carbons (ACs) have received remarkable attention [18,24-26], owing to high specific surface area, high pore volume, micro- or mesoporosity, tunable surface chemistry, and reasonable cost. These features are crucial to achieve high performance in sorbent materials at low cost. In this context, it is important to consider that the textural properties of ACs are tightly related to the raw materials used as precursors and the method of preparation [27]. Activated carbon production usually comprises two-steps [27]. First, the precursor is carbonized through pyrolysis at high temperatures or hydrothermal carbonization at mild temperatures. In the second step, the hydro- or pyrochars are submitted to an activation process, with the aim of increasing the surface area. In order to reduce the production cost, porous carbon materials and activated carbons are commonly obtained using raw biomass and carbohydrates as precursors [27]. Natural precursors rich in structural heteroatoms (e.g., chitosan) have been less investigated but are particularly attractive as they offer the chance of producing hetero-doped carbon structures with additional functionalities of interest for several applications $[28,29]$.
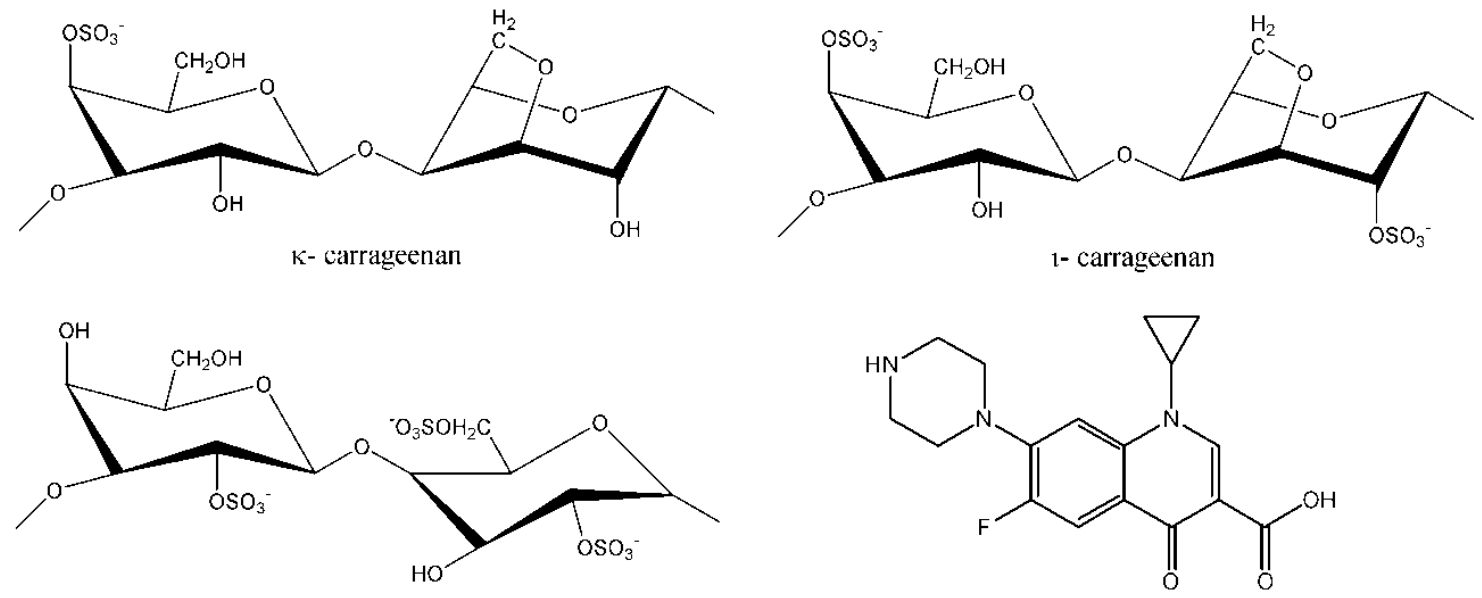

$\lambda$ - carrageenan

ciprofloxacin

Scheme 1. Structural formulas of the disaccharide units of $k$-, $l$ - and $\lambda$-carrageenan, and ciprofloxacin.

Carrageenan is a family of linear sulfated polysaccharides composed of galactose and anhydrogalactose units, extracted from red seaweeds [30]. The most commonly used are k-, $\iota$ - and $\lambda$-carrageenan, that comprise one, two or three sulfated groups per disaccharide unit, respectively (Scheme 1). Carrageenans have been widely used as emulsifying or gelling agents in the pharmaceutical and food industries [30,31]. Owing to its natural abundance and chemical functionality, carrageenan have attracted attention for sorption applications, namely in the uptake of pesticides and pharmaceutical contaminants from water [32-35]. However, to the best of our knowledge, carrageenan has been scarcely investigated as a carbon source to prepare porous carbon materials. Furthermore, 
studies on carrageenan-derived porous carbons were limited to energy-related applications [36,37]. For example, Fan and co-workers [37] reported that mesoporous carbon microspheres prepared from carrageenan (undefined type) present good electrochemical capacitive performance owing to high surface area, narrow pore size distribution and optimized micro- and mesoporous structure.

In this work, we have investigated the use of three distinct carrageenans with variable sulfate content ( $\mathrm{K}-\mathrm{l} \mathrm{l}-$ and $\lambda$-carrageenan) as precursors submitted to hydrothermal carbonization in the preparation of activated carbons and subsequent chemical activation with potassium hydroxide $(\mathrm{KOH})$. Furthermore, we have explored the application of the prepared materials as sorbents for the removal of the antibiotic ciprofloxacin from aqueous solutions.

\section{Materials and Methods}

\subsection{Chemicals}

Three types of carrageenan ( $\kappa, \iota$ and $\lambda$-carrageenan) were acquired from Honeywell Fluka (Seelze, Germany). Potassium hydroxide ( $>86 \%$ ) was purchased from Labchem (Zelienople, PA, USA) and hydrochloride acid $(\mathrm{HCl}, 37 \% v / v)$ was purchased from VWR International (Radnor, PA, USA). Ciprofloxacin hydrochloride (99\%) was purchased from Sigma-Aldrich (St. Louis, MO, USA). Milli-Q water was obtained through Synergy equipment (Millipore, $0.22 \mu \mathrm{m}$ filter) and absolute ethanol $\left(\mathrm{CH}_{3} \mathrm{CH}_{2} \mathrm{OH}\right)$ was purchased from Honeywell Fluka (Seelze, Germany).

\subsection{Preparation of the Activated Carbons}

Synthesis of the activated carbons involved two main steps, a hydrothermal treatment of the carrageenan, followed by chemical activation [37]. In a typical procedure, $0.87 \mathrm{~g}$ of carrageenan $(\mathrm{K}$, $\iota$ or $\lambda$-carrageenan) were dissolved in water $(17.5 \mathrm{~mL})$ under stirring, placed in a Teflon autoclave and subjected to $200{ }^{\circ} \mathrm{C}$ for $20 \mathrm{~h}$. The resulting hydrochar, a dark precipitate, was collected by centrifugation (15 min, $6000 \mathrm{rpm}$, Hettich Zentrifugen, EBA 20), washed with water and ethanol several times, and freeze-dried (Coolsafe Touch, Labogene). The hydrochars were identified according to their carrageenan precursor-HC- $\kappa, \mathrm{HC}-\iota$ and $\mathrm{HC}-\lambda$. These materials were chemically activated by $\mathrm{KOH}$ in a 1:4 $\mathrm{HC}: \mathrm{KOH}$ weight ratio (physical mixture) in a tube furnace, under nitrogen atmosphere, at $700{ }^{\circ} \mathrm{C}\left(4^{\circ} \mathrm{C} / \mathrm{min}\right)$ for $4 \mathrm{~h}$. The obtained materials were washed with hydrochloric acid (2 M), followed by water to remove all potassium, and then suspended in ethanol and dried at $60{ }^{\circ} \mathrm{C}$ overnight. The resulting activated carbons were identified as AC- $\kappa, A C-\iota$ and AC- $\lambda$ according to their AC precursor.

\subsection{Adsorption Experiments}

The ability of the activated carbons to uptake ciprofloxacin (CIP) from water was assessed through batch adsorption experiments in polypropylene containers. AC samples were precisely weighted and added to a CIP aqueous solution of known concentration in deionized water and were continuously shaken using a vertical rotator at a constant rotation speed $(30 \mathrm{rpm})$ under isothermal conditions $\left(25 \pm 1{ }^{\circ} \mathrm{C}\right)$. The starting point of the uptake experiment was coincident with the beginning of the stirring process. A comparison between the adsorption performances of the $\mathrm{HC}$ and $\mathrm{AC}$ materials was preliminary assessed by using $0.5 \mathrm{mg} / \mathrm{mL}$ of carbon at $\mathrm{pH}$. CIP solutions were prepared daily by diluting the corresponding stock solution. In each experiment, aliquots were collected for analysis at different times. The carbon materials were separated from the medium by centrifugation $(13,300 \mathrm{rpm}$, $5 \mathrm{~min}$, Spectrafuge 24D, Labnet). The concentration of CIP in the supernatant was determined by measuring the absorbance at $273 \mathrm{~nm}$ using a UV-Vis spectrophotometer (Cintra 303, GBC). The calibration curve was built with CIP standards with concentrations between 0.12 and $12 \mathrm{mg} / \mathrm{L}$.

The amount of adsorbed CIP at time $t\left(q_{t}\right.$ in $\left.\mathrm{mg} / \mathrm{g}\right)$ was estimated from the mass balance between the initial CIP concentration $\left(C_{0}\right.$ in $\left.\mathrm{mg} / \mathrm{L}\right)$ and concentration at time $t\left(C_{t}\right.$ in $\left.\mathrm{mg} / \mathrm{L}\right)$ in the solution, 
as displayed by Equation (1), where $V$ is the total volume of CIP solution (L) and $m$ is the mass of the dry weight of the sorbent.

$$
q_{t}=\frac{\left(C_{0}-C_{t}\right) V}{m}
$$

The removal percentage (R) of CIP was calculated using Equation (2):

$$
R=\frac{C_{0}-C_{t}}{C_{0}} \times 100
$$

Control uptake experiments, i.e., in the absence of carbon materials, were also carried out in parallel under the same conditions to inquire about CIP losses due to adverse effects.

\subsubsection{Effect of $\mathrm{pH}$, Sorbent Dosage and Equilibrium Isotherms}

The effect of $\mathrm{pH}$ on adsorption was firstly investigated. The $\mathrm{pH}$ of CIP solutions was adjusted using ammonia (25\%) or hydrochloric acid (37\%). Then the adsorption capacity at equilibrium $\left(q_{e}\right)$ was determined at $\mathrm{pH} 6$ and $24 \mathrm{~h}$ contact time for an initial CIP concentration of $50 \mathrm{mg} / \mathrm{L}$ with variable sorbent dosage $(0.05,0.1,0.25,0.4$ and $0.5 \mathrm{mg} / \mathrm{mL}$ of $\mathrm{AC})$. The amount of adsorbed CIP at equilibrium $\left(q_{e}, \mathrm{mg} / \mathrm{g}\right)$ was assessed by UV-Vis spectroscopy and calculated using Equation (1) for $C_{t}=C_{e}$, where $C_{e}(\mathrm{mg} / \mathrm{L})$ is the concentration of CIP at equilibrium. The isotherm curves were built by plotting $q_{e}$ against $C_{e}(\mathrm{mg} / \mathrm{L})$.

\subsubsection{Effect of Contact Time}

To investigate the kinetics of adsorption, the time profile of CIP adsorption was assessed. Typically, $10 \mathrm{mg}$ of activated carbon (accurately weighted) were added to $20 \mathrm{~mL}$ of CIP solution (50 mg/L, $\mathrm{pH}$ ). With the mixture being shaken, aliquots of $0.7 \mathrm{~mL}$ were collected over time, at $25.0 \pm 1.0{ }^{\circ} \mathrm{C}$. The amount of CIP adsorbed onto the AC samples at each time interval $\left(q_{t}, \mathrm{mg} / \mathrm{g}\right)$ was determined using Equation (1) and plotted against time $(t, \mathrm{~min})$.

\subsection{Materials Characterization}

Nitrogen physisorption experiments were performed with a Gemini V2.0 Micromeritics Instrument (Micromeritics, Norcross, GA, USA) to investigate the textural properties of the carbonaceous materials. The specific surface area of the materials was determined from $\mathrm{N}_{2}$ adsorption/ desorption isotherms, using the Brunauer-Emmett-Teller (BET) equation [38]. The total pore volume $\left(V_{T}\right)$ was defined as the volume of liquid nitrogen corresponding to the amount adsorbed at a relative pressure $p / p_{0}=0.99$ (Gurvitch rule) [39]. The micropore volume, $V_{\text {micro, }}$ was calculated according to the Dubinin-Radushkevitch method [40]. The average pore size $\left(d_{P}\right)$ was calculated using the ratio $4 V_{T} / S_{B E T}$ that considers pores with cylindrical shape. Elemental analysis of carbon, hydrogen and sulphur was performed on a Leco Truspec-Micro CHNS 630-200-200 (LECO, Saint Joseph, MI, USA). Fourier transform infrared (FTIR) spectra of the materials were obtained using a Bruker Optics Tensor 27 spectrometer (Bruker, Billerica, MA, USA) coupled to a horizontal attenuated total reflectance (ATR) cell, using 256 scans at $4 \mathrm{~cm}^{-1}$ resolution. Raman spectra were acquired in a combined Raman-AFM confocal microscope WITec alpha300 RAS+ (WITec, Ulm, Germany). An Nd:YAG laser operating at $532 \mathrm{~nm}$ was used as excitation source with the power set to $1 \mathrm{~mW}$. A $100 \times$ objective was used to view samples with an integration time of $2 \mathrm{~s}$ for each spectrum and 10 acquisitions. The intensity values of the Raman bands of the carbon materials for the ratio $\mathrm{I}_{\mathrm{D}} / \mathrm{I}_{\mathrm{G}}$ calculation were obtained by fitting the Gaussian function in Project five ${ }^{+}$software (WITec, Ulm, Germany). The carbon materials were analysed by powder X-ray diffraction (XRD) in a Rigaku Geigerflex Dmax-C diffractometer (Rigaku, Tokyo, Japan) equipped with a $\mathrm{CuK} \alpha$ monochromatic radiation source with $0.026^{\circ}$ as step size and $350 \mathrm{~s}$ as time per step. The morphology and size of the particles was analysed by scanning electron microscopy (SEM) using a Hitachi Su-70 microscope (Hitachi, Tokyo, Japan) operating at $15 \mathrm{kV}$. Samples for electron microscopy analysis were prepared by evaporating particle suspensions 
(in ethanol) on a cooper grid coated with an amorphous carbon film. Zeta potential measurements were performed in aqueous solutions of the particles to assess the surface charge of the particles, using Zetasizer Nano ZS equipment from Malvern Instruments (Malvern, United Kingdom).

\section{Results and Discussion}

\subsection{Characterization of the Carbon Materials}

The electron microscopy analysis of the HCs and ACs prepared using different carrageenan types as precursors unveiled distinct morphological and microstructural features (Figure 1). The hydrothermal carbonization of carrageenan produced spheroidal carbon particles with a smooth surface and an average diameter between 3 and $5 \mu \mathrm{m}$, respectively (Figure 1 and Table 1). Hydrothermal carbonization of $\lambda$-carrageenan formed bottleneck junctions between adjacent HC- $\lambda$ particles. Upon activation with $\mathrm{KOH}$ the particle size decreased drastically to nanometric dimensions, with the average size ranging between 50 and $150 \mathrm{~nm}$, and the particles exhibited a rough surface. The spherical shape of the hydrochars $\mathrm{HC}-\iota$ and $\mathrm{HC}-\lambda$ was preserved after $\mathrm{KOH}$ activation, in agreement with previous findings reported for spherical-activated carbons prepared from carrageenan (undefined type) using identical $\mathrm{KOH}$ activation conditions [37]. In contrast, the activated carbons prepared from K-carrageenan presented irregular shape.

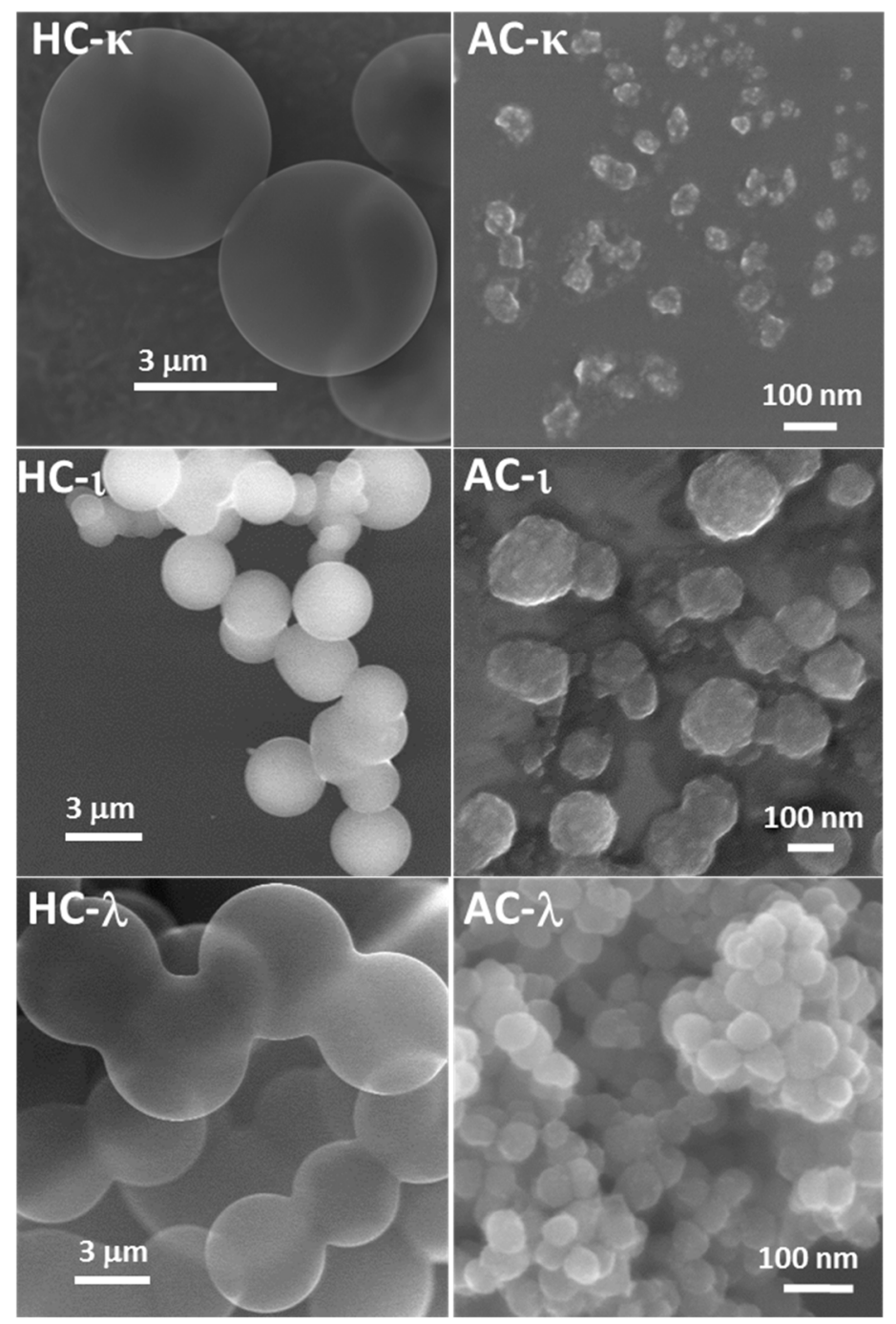

Figure 1. Electron micrographs of carrageenan-derived hydrochars (left) and activated carbons (right). 
Table 1. Morphological and compositional properties of the hydrochars and activated carbons.

\begin{tabular}{|c|c|c|c|c|c|}
\hline Sample & $D_{S E M}(\mu \mathrm{m} / \mathrm{nm})^{a}$ & $C(w t \%)^{b}$ & $H(w t \%)^{b}$ & $S\left(w t^{\prime}\right)^{b}$ & $O\left(w t^{\%}\right)^{b}$ \\
\hline $\mathrm{HC}-\mathrm{k}$ & $3.98 \pm 1.63 \mu \mathrm{m}$ & 70.734 & 4.453 & u.l.d. ${ }^{c}$ & 24.813 \\
\hline $\mathrm{HC}-\mathrm{\iota}$ & $2.97 \pm 1.18 \mu \mathrm{m}$ & 71.214 & 4.479 & 0.356 & 23.951 \\
\hline $\mathrm{HC}-\lambda$ & $4.92 \pm 0.48 \mu \mathrm{m}$ & 67.141 & 4.112 & u.l.d ${ }^{c}$ & 28.747 \\
\hline$A C-k$ & $45.9 \pm 22.8 \mathrm{~nm}$ & 89.592 & 0.592 & u.l.d ${ }^{c}$ & 9.816 \\
\hline$A C-\iota$ & $157.3 \pm 51.5 \mathrm{~nm}$ & 73.315 & 3.266 & u.l.d ${ }^{c}$ & 23.419 \\
\hline$A C-\lambda$ & $54.1 \pm 14.3 \mathrm{~nm}$ & 78.879 & 0.418 & u.l.d ${ }^{\mathrm{c}}$ & 20.703 \\
\hline
\end{tabular}

a Particle diameter measured using SEM. ${ }^{\mathrm{b}}$ Carbon, hydrogen and sulfur content measured by elemental microanalysis. Oxygen content calculated by difference ${ }^{\mathrm{c}}$ under the limit of instrumental detection.

Among the hydrochars, HC- $\lambda$ presented the highest oxygen content as determined by elemental microanalysis. Although carrageenans are sulphonated polysaccharides, sulfur was detected in a vestigial amount only for l-carrageenan-derived hydrochars (0.4 wt\%) (Table 1). As expected on the basis of previous studies, activation with $\mathrm{KOH}$ resulted in an increase of carbon content and a decrease of oxygen content in the materials prepared from $\mathrm{k}$ - and $\lambda$ - carrageenan [41]. Unexpectedly, the activation barely affected the elemental composition of $\iota$-carrageenan-derived $\mathrm{AC}$, whose carbon content was lower than in the other activated carbons, but has higher oxygen content.

The textural properties of the hydrochars and the activated carbons were analyzed by $\mathrm{N}_{2}$ sorption/desorption technique. The results are included in Table 2. The hydrochars have a specific surface area $\left(S_{B E T}\right)$ between 4.9 and $30 \mathrm{~m}^{2} / \mathrm{g}$ and low total porosity $\left(V_{T}\right)$, which are comparable with the values reported for hydrochars prepared from polysaccharides [37]. The $S_{B E T}$ was higher for HC-ı spheres, which is in line with the smaller average particle size observed in SEM images, combined with the higher value of total porosity. The surface area markedly increased through $\mathrm{KOH}$ activation in agreement with the decrease of particle size and increase of surface roughness observed by electron microscopy analysis. Furthermore, the activation process makes the carbons highly porous, as expected on the basis of previous works [42,43]. Noteworthy, all ACs present a specific surface area above $2300 \mathrm{~m}^{2} / \mathrm{g}$, and up to $2800 \mathrm{~m}^{2} / \mathrm{g}$ for the AC derived from l-carrageenan, which are values superior to the specific surface area of commercial activated carbons [44]. The $\mathrm{N}_{2}$ adsorption-desorption isotherms (77 K) are type I (Figure 2), which is characteristic of materials with marked microporous character [45]. The volume of micropores $\left(V_{\text {micro }}\right)$ calculated using the Dubinin-Radushkevitch equation was high for all AC samples, from 0.8 to $1.1 \mathrm{~cm}^{3} / \mathrm{g}$, and is in line with the microporosity features demonstrated in the isotherm profile.

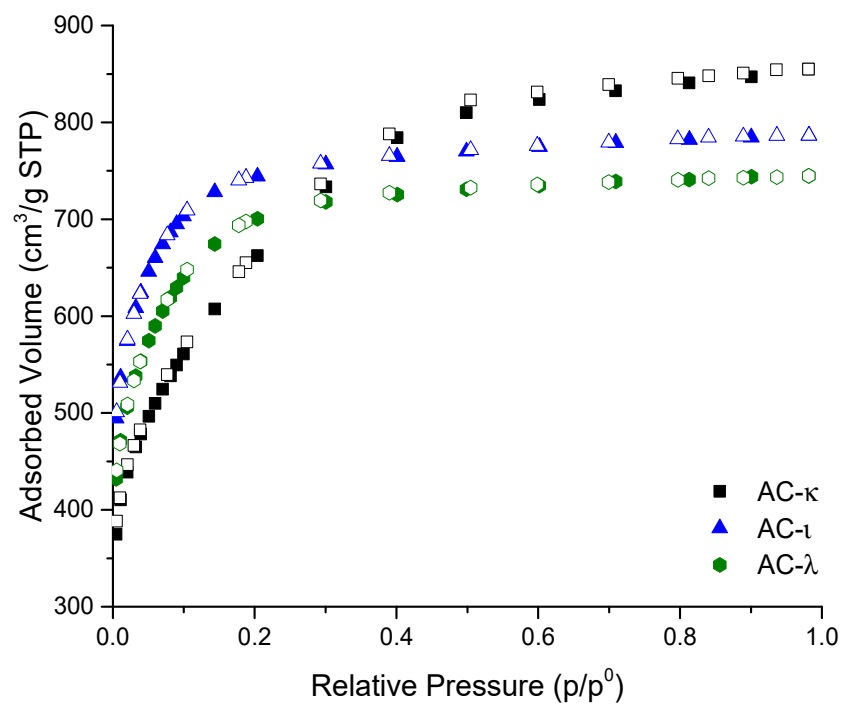

Figure 2. $\mathrm{N}_{2}$ adsorption (full symbols) and desorption (empty symbols) isotherms for activated carbons at $77 \mathrm{~K}$. 
Table 2. Textural properties of the hydrochars and activated carbons.

\begin{tabular}{ccccc}
\hline Sample & $S_{\text {BET }}\left(\mathbf{m}^{2} / \mathbf{g}\right)$ & $V_{T}\left(\mathbf{c m}^{3} / \mathbf{g}\right)$ & $V_{\text {micro }}\left(\mathbf{c m}^{3} / \mathbf{g}\right)$ & $d_{P}(\mathbf{n m})$ \\
\hline HC- & 4.88 & 0.0070 & - & 5.4 \\
HC-l & 30.44 & 0.0245 & - & 3.8 \\
HC- $\lambda$ & 11.89 & 0.0107 & - & 5.2 \\
AC- $-\kappa$ & 2345.6 & 1.336 & 0.836 & 2.3 \\
AC- & 2804.9 & 1.229 & 1.087 & 1.8 \\
AC- $\lambda$ & 2515.8 & 1.164 & 0.968 & 1.9 \\
\hline
\end{tabular}

The powder XRD of the hydrochars shows a single broad feature centered at $23^{\circ}$ corresponding to (002) of graphite, which suggests a material composed of amorphous carbon with low graphitization (Figure 3 and Figure S1, Supporting Information) [37]. The absence of marked reflection peaks in the XRD patterns of activated carbons indicates that the level of structure order decreases after activation.

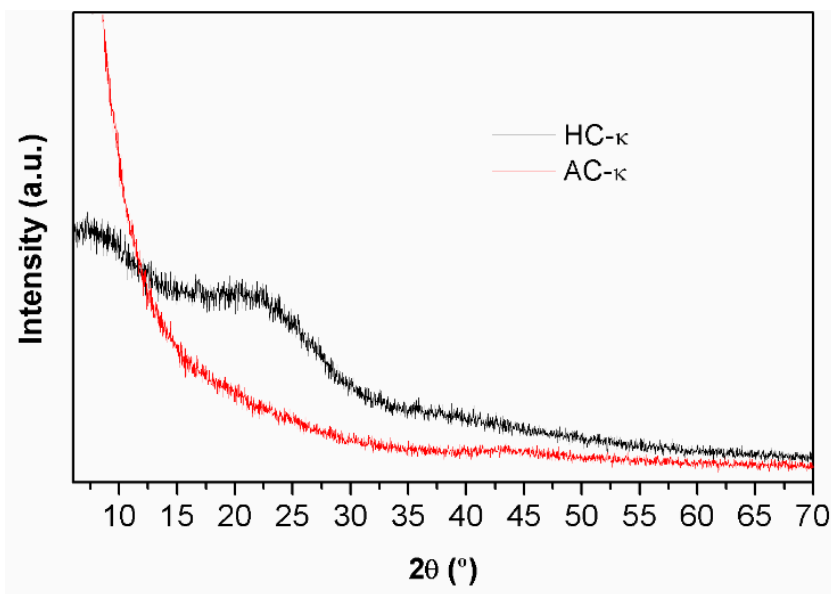

Figure 3. Powder XRD pattern of $\kappa$-carrageenan-derived hydrochar (HC) and activated (AC) carbons.

Figure $4 \mathrm{a}$ depicts the Raman spectra of the materials before and after activation with $\mathrm{KOH}$. The spectra show two bands at around $1360 \mathrm{~cm}^{-1}$ (D band) and $1586 \mathrm{~cm}^{-1}$ (G band) which are typical of carbon materials. The $\mathrm{G}$ band is attributed to the $\mathrm{C}-\mathrm{C}$ bond in ordered graphitic structures and indicates the presence of $\mathrm{sp}^{2}$-hybridized $\mathrm{C}$ atoms present in materials such as graphene, carbon nanotubes and amorphous carbon [46]. The $\mathrm{D}$ band denotes the presence of defects and disorder in the $\mathrm{sp}^{2}$ structure, namely due to the presence of $\mathrm{sp}^{3}$-hybridized carbon atoms. The intensity ratio between the D-band and G-band $\left(I_{D} / I_{G}\right)$ is an important parameter to monitor the disorder in the carbon structure of the materials. The $I_{D} / I_{G}$ ratio was identical in the hydrothermal carbons prepared from $k$ - and $\lambda$-carrageenan and slightly lower when l-carrageenan was used. Overall, the $I_{D} / I_{G}$ value increased after activation, which indicates that the degree of graphitization decreased after $\mathrm{KOH}$ activation. This is in line with previous works that reported that activation with $\mathrm{KOH}$ at high temperatures $\left(700-900{ }^{\circ} \mathrm{C}\right)$ and high $\mathrm{KOH} / \mathrm{C}$ ratios $(4: 1$ and $3: 1, w / w)$ favors the conversion of the conjugated aromatic structure into $\mathrm{sp}^{3}$-hybridized $\mathrm{C}$ atoms $[37,47]$.

The chemical identity of the carbon materials before and after activation was assessed by ATR-FTIR spectroscopy (Figure 4b) and the most relevant bands were assigned as depicted in Table S1 (Supporting Information). All hydrochars exhibited a broad band at $3000-3600 \mathrm{~cm}^{-1}$ that is ascribed to $\mathrm{O}-\mathrm{H}$ stretching vibrations from surface hydroxyl groups and adsorbed water molecules. The bands at 2929 and $2879 \mathrm{~cm}^{-1}$ confirm the presence of aliphatic carbons, $-\mathrm{CH}_{2}$ - and $-\mathrm{CH}_{3}$ [48]. The overlapping bands with peaks at $1695 \mathrm{~cm}^{-1}$ and $1606 \mathrm{~cm}^{-1}$ are due to carbonyl $(C=O)$ stretching vibrations and the stretching of $\mathrm{C}=\mathrm{C}$ in aromatic rings, respectively [49]. The broad band at $1298 \mathrm{~cm}^{-1}$ is ascribed to C-O bending vibrations [50]. The band at $798 \mathrm{~cm}^{-1}$ is attributed to the $\mathrm{C}-\mathrm{H}$ vibration in aromatic 
structures [49]. After activation, the bands due to $\mathrm{OH}, \mathrm{C}=\mathrm{O}$ and $\mathrm{C}-\mathrm{O}$ vibrations are less intense (or not observed), which indicates the decrease of surface functionalization with oxygen-containing groups. The band at $798 \mathrm{~cm}^{-1}$ disappears, which indicates the decrease of aromatization after activation and is in agreement with the Raman observations presented above. Still, vibrations of aromatic $\mathrm{C}=\mathrm{C}$ bonds can be detected through the most intense band in the region $1520-1560 \mathrm{~cm}^{-1}$ [48].

(a)

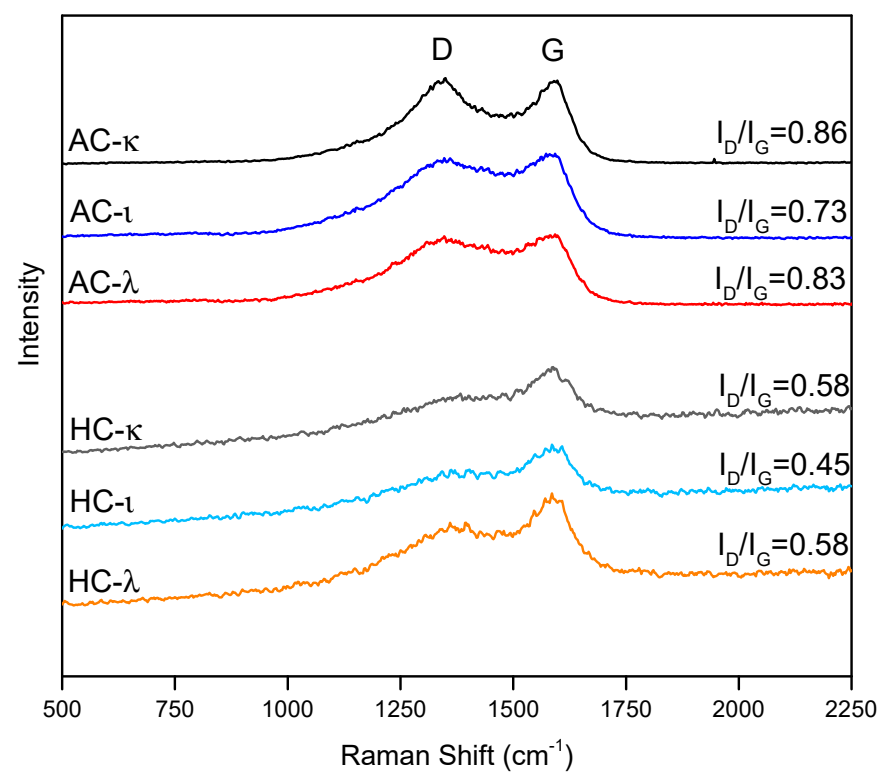

(b)

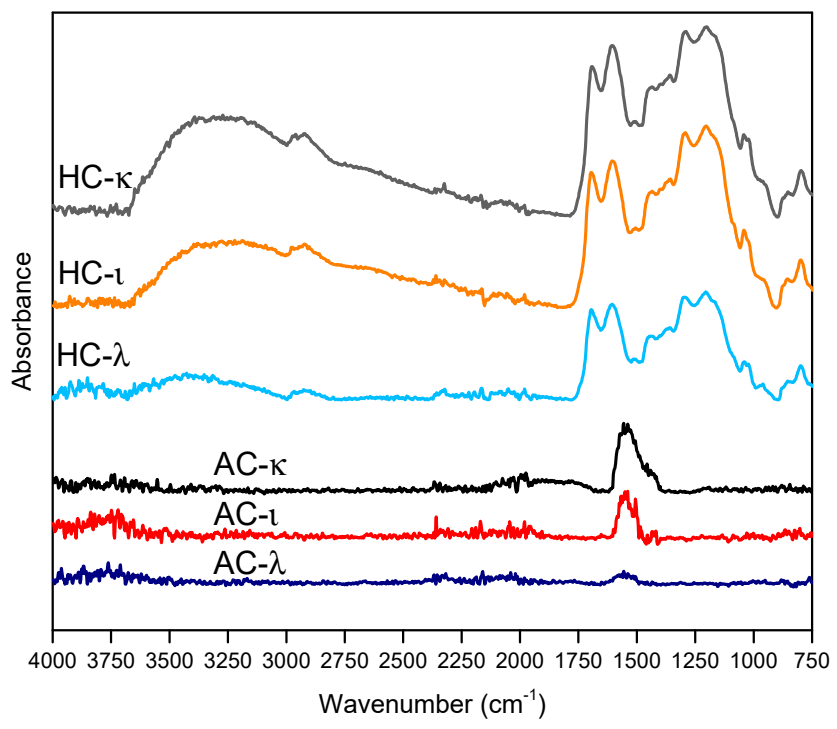

Figure 4. Raman (a) and ATR-FTIR (b) spectra of hydrochars (HC) and activated (AC) carbons.

Determination of zeta potential $(\zeta)$ was performed to assess the surface charge of the carbon materials. The measurements were performed at $\mathrm{pH}$ ranging from approximately 5 to 9 , which includes the normal range for $\mathrm{pH}$ in surface water systems (6.5-8.5). Zeta potential measurements revealed that all the carbon materials display a negative surface within the $\mathrm{pH}$ range tested (Figure 5). Negative $\zeta$-values in the hydrochars are due to ionized oxygen containing groups present at the surface of the carbons. Overall, the $\zeta$-values of activated carbons range from ca. $-10 \mathrm{mV}$ at $\mathrm{pH} 5$ to $-30 \mathrm{mV}$ at pH 8.5 and are less negative than in hydrochars, which is in line with elemental microanalysis and FTIR results that denote a decrease of oxygen-containing groups after activation. However, highly negative surface charge of activated carbons at $\mathrm{pH}$ values above 7 suggests high colloidal stability of these materials and strong stability against aggregation that could favor the adsorptive properties. 


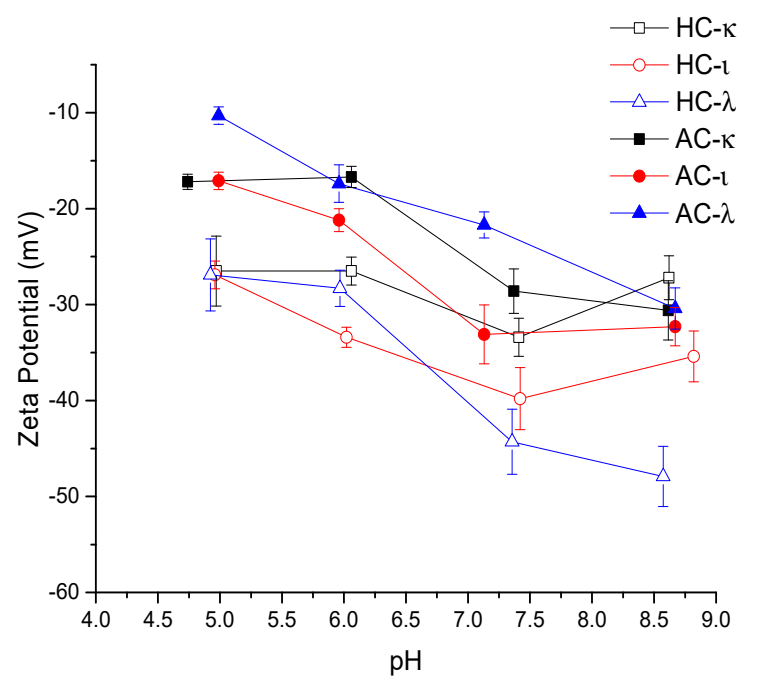

Figure 5. Zeta potential titration for hydrochars and activated carbons.

\subsection{Uptake of Ciprofloxacin From Water}

The performance of the carbonaceous materials before and after $\mathrm{KOH}$ activation in the uptake of ciprofloxacin was investigated for the same initial concentration of CIP $(50 \mathrm{mg} / \mathrm{mL}$, deionized water) at $\mathrm{pH} 5$, with $24 \mathrm{~h}$ contact time. The results clearly show that activated carbons have a higher capacity to adsorb CIP than the hydrochars (Figure 6). Overall, the CIP removal by hydrochars is very low $(<10 \%)$ but increases to values above $99 \%$ when activated carbons are used in similar operational conditions.

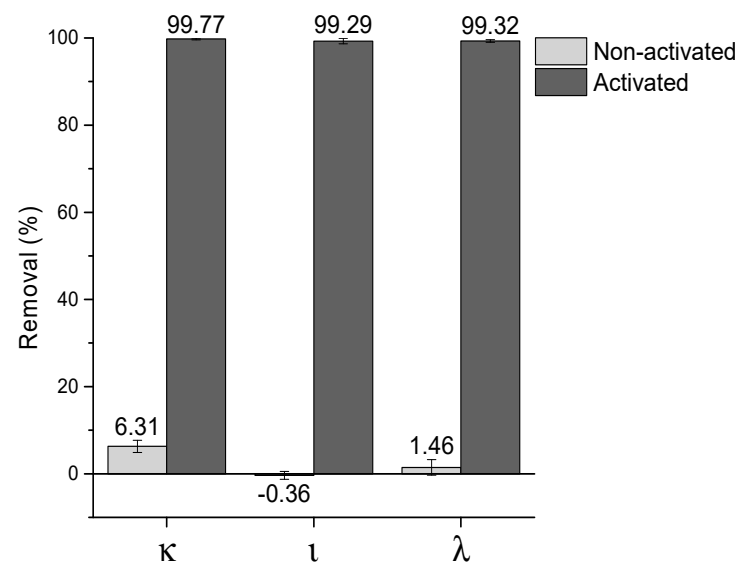

Figure 6. The performance of the hydrochars and activated carbons for the removal of ciprofloxacin from water (conditions: $50 \mathrm{mg} / \mathrm{L} \mathrm{CIP,} \mathrm{pH}=5,24 \mathrm{~h}$ contact time, sorbent dosage: $0.5 \mathrm{mg} / \mathrm{mL}$ ).

\subsubsection{Effect of $\mathrm{pH}$ on Adsorption in Aqueous Medium}

The adsorptive performance of the activated carbons was investigated in the $\mathrm{pH}$ range 5-9 for $24 \mathrm{~h}$ contact time for an ciprofloxacin (CIP) concentration of $50 \mathrm{mg} / \mathrm{L}$ (Figure 7). Control experiments were carried out in parallel without sorbents and under similar conditions of $\mathrm{pH}$ and contact time, and have shown negligible losses of CIP $(<2 \%$, data not shown). Therefore, the decrease of CIP concentration in the presence of the activated carbons was ascribed to adsorption phenomena. The CIP removal was above $99 \%$ for $\mathrm{pH}$ values between 5 and 7 , and slightly decreased to $98-99 \%$ at $\mathrm{pH}=8.8$. According to the zeta potential results (Figure 5), all the ACs present a negatively charged surface for $\mathrm{pH}$ 5-9. However, CIP is present in the form of distinct ionic species within this $\mathrm{pH}$ range (Figure S2, Supporting Information) [51,52]. At $\mathrm{pH}=5, \mathrm{CIP}$ is mainly in the cationic form due to protonation of the aminic groups but at $\mathrm{pH}=7$ it is mostly as zwitterions. Both forms contain protonated amine 
groups that could interact electrostatically with the negatively charged surface of the carbons. Still, at $\mathrm{pH}=8.8$ about half of the CIP molecules are in the anionic form and thus are less prone to interact with the sorbent's surface via electrostatic interactions. This could explain the decrease on the CIP adsorption at $\mathrm{pH}=8.8$ and suggests that cation- $\pi$ interactions between CIP molecules and $\pi$-electrons of the carbon structure play a role in the sorption mechanism [53]. Yet, even at $\mathrm{pH}=8.8$ the removal capacity was high. This indicates that the sorption mechanism may involve other pathways such as $\pi-\pi$ interactions, hydrogen bonding and hydrophobic interactions [54]. The kinetics and equilibrium studies were performed at $\mathrm{pH} 6$, which is within the normal range of $\mathrm{pH}$ in surface water systems.

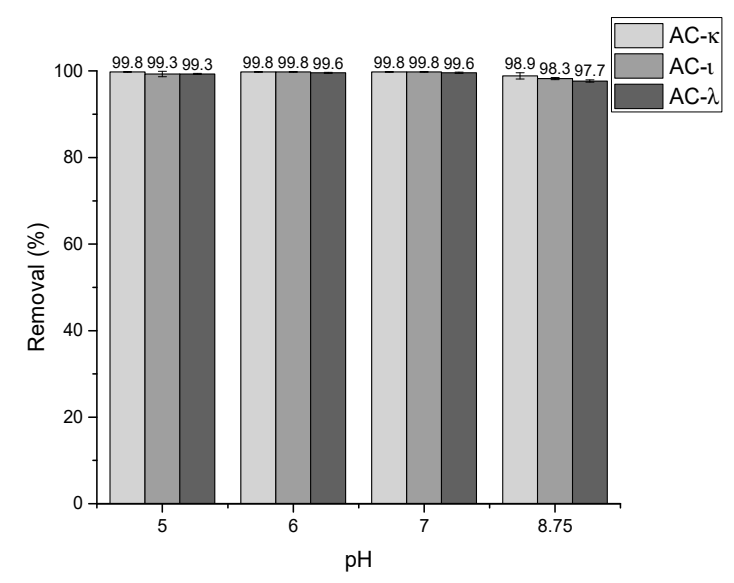

Figure 7. Removal of ciprofloxacin $(50 \mathrm{mg} / \mathrm{L})$ from water samples at distinct $\mathrm{pH}$ using the activated carbons (conditions: $24 \mathrm{~h}$ contact time, sorbent dosage: $0.5 \mathrm{mg} / \mathrm{mL}$ ).

\subsubsection{Effect of Adsorbent Dosage}

The effect of the adsorbent dose on the adsorption of ciprofloxacin was investigated in the range 0.05 to $0.5 \mathrm{mg} / \mathrm{mL}$. The results (Figure 8) show that CIP removal increases with the increase of the amount of sorbent until it reaches a plateau. At $0.25 \mathrm{mg} / \mathrm{mL}$ or higher dosages, all the carbons display a good performance ( $\geq 98-99 \%$ ) in the removal of ciprofloxacin. At a dosage of $0.1 \mathrm{mg} / \mathrm{mL}$, the removal

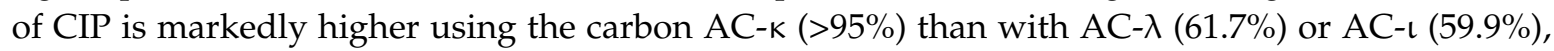
which suggests a better adsorption performance for the activated carbon prepared from $\mathrm{k}$-carrageenan.

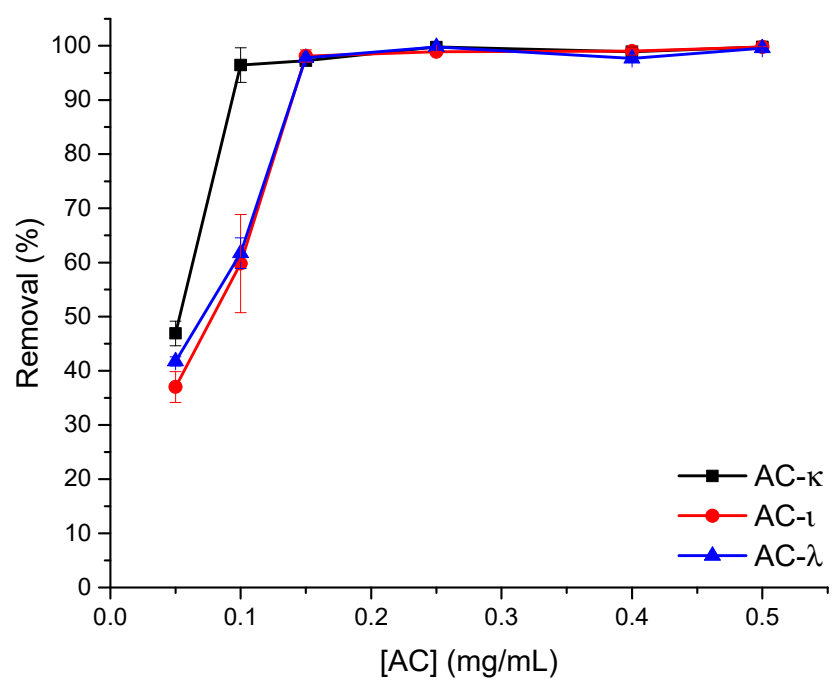

Figure 8. Effect of the adsorbent dosage in the removal of CIP from water, using the carrageenan-based activated carbons (conditions: $50 \mathrm{mg} / \mathrm{L} \mathrm{CIP,} \mathrm{pH}=6,24$ h contact time). 


\subsubsection{Isotherm Studies}

The equilibrium adsorption capacity of $\mathrm{CIP}\left(\mathrm{q}_{\mathrm{e}}\right)$ as a function of equilibrium concentration of CIP $\left(C_{e}\right)$ is depicted in Figure 9. The equilibrium data were analyzed using several common isotherm models: the Langmuir [55] and Freundlich [56] isotherms, which are two-parameter isotherms, and the Sips isotherm [57,58], also named the Langmuir-Freundlich method, which is a three-parameter isotherm (See Table S2, Supporting Information for model equations). The isotherm equations were fitted to experimental data by nonlinear regression analysis. The goodness of the fitting was assessed based on the analysis of the correlation coefficient $\left(R^{2}\right)$ and Chi-square test value $\left(\chi^{2}\right)$ (Equations (S1) and (S2), Supporting Information). The goodness of the fittings and model parameters are shown in Table 3.

Overall, the Sips model provides the best correlation with the experimental data, with $R^{2}$ ranging from 0.9315 to 0.9808 . The Sips (or Langmuir-Freundlich) isotherm is, as the name indicates, a combination of Langmuir and Freundlich isotherms. At low sorbate concentration, the Sips equation reduces to a Freundlich isotherm, while at high sorbate concentrations, it predicts the sorption capacity of a monolayer, characteristic of the Langmuir isotherm. [59]. This isotherm is capable of modeling both homogeneous and heterogeneous binding surfaces. The exponent $m$ is the heterogeneous index that varies from 1 , in a homogeneous surface, to $m<1$, in a heterogeneous surface. For AC-l, $m=1$ indicates that the surface of this sorbent is homogeneous, i.e., all binding sites are energetically equivalent. In this case, the Sips isotherm is reduced to Langmuir isotherm and the parameter $a$ corresponds directly to the Langmuir isotherm constant $\mathrm{K}_{\mathrm{L}}$ (Table 3). Whereas the value of the exponent $m$ on Sips equation was $<1$ for both $A C-\kappa$ and $A C-\lambda$, which indicates heterogeneous surfaces in these sorbents. For AC- $\lambda$, both $a$ and $m$ approaches 0 and the Sips equation tends to reduce to Freundlich isotherm. Indeed, for this AC the goodness of fit by Sips and Freundlich models was identical. The Freundlich isotherm is an empirical model with wide application in heterogeneous systems, which assumes that the adsorption could take place via multiple layers instead of a single layer [56].
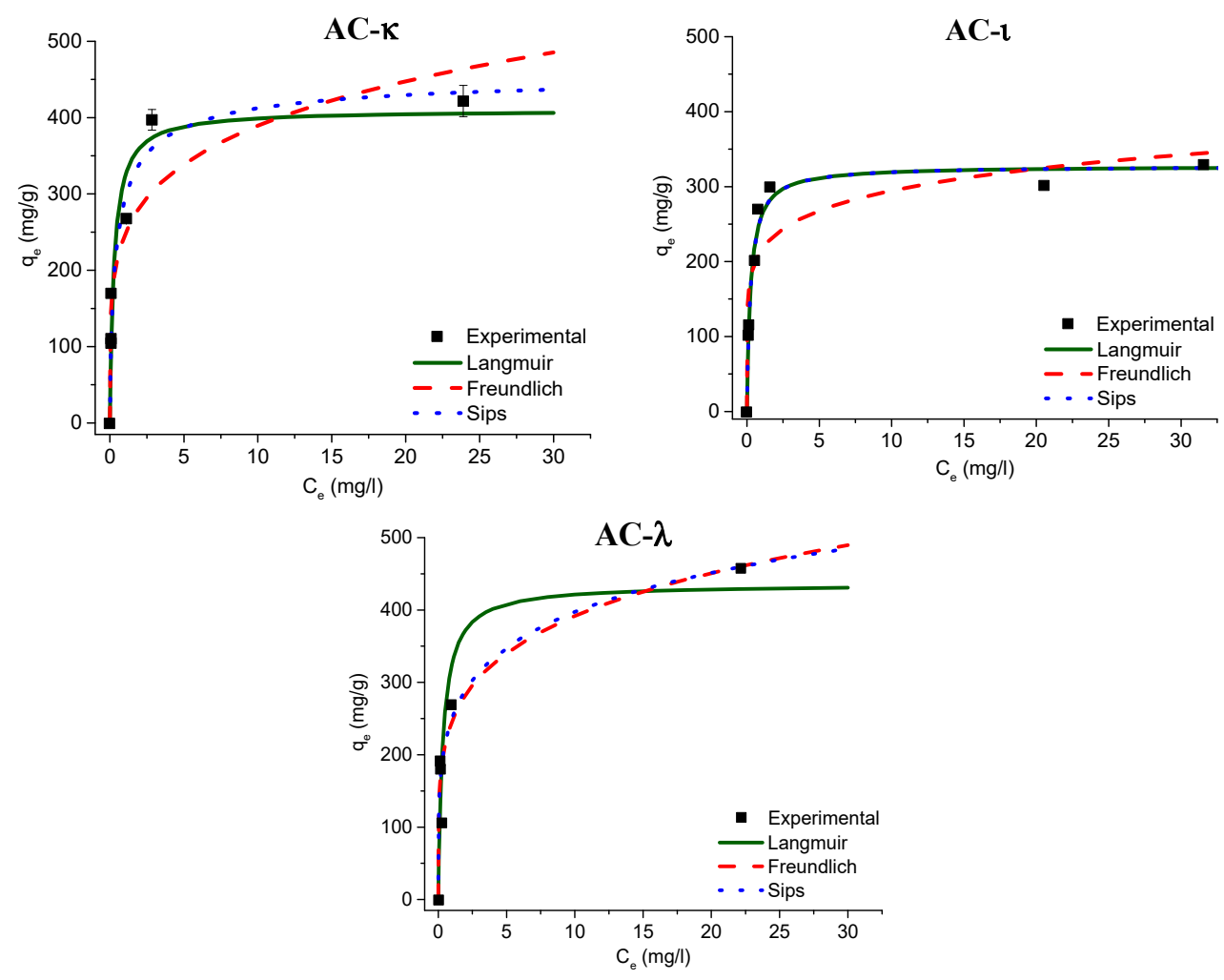

Figure 9. Isotherm data and the corresponding model fitting for the adsorption of ciprofloxacin on the activated carbons. 
Table 3. Equilibrium model parameters and goodness of fittings.

\begin{tabular}{|c|c|c|c|c|c|c|}
\hline Isotherm & Sample & Mode & arameters & & Good & f Fit \\
\hline \multirow{4}{*}{ Langmuir } & & $q_{L}\left(\mathrm{mg} \cdot \mathrm{g}^{-1}\right)$ & $K_{L}\left(\mathrm{~L} \cdot \mathrm{mg}^{-1}\right)$ & & $R^{2}$ & $x^{2}$ \\
\hline & AC-k & 410.1 & 3.616 & & 0.9494 & 40.06 \\
\hline & AC-ı & 327.5 & 3.907 & & 0.9808 & 7.412 \\
\hline & $\mathrm{AC}-\lambda$ & 435.6 & 2.941 & & 0.8528 & 131.1 \\
\hline \multirow{4}{*}{ Freundlich } & & $K_{F}\left(\mathrm{mg}^{(1-1 / \mathrm{n})} \cdot \mathrm{L}^{(1 / \mathrm{n})} \cdot \mathrm{g}^{-1}\right)$ & $n$ & & $R^{2}$ & $x^{2}$ \\
\hline & $A C-k$ & 245.6 & 4.991 & & 0.8943 & 66.59 \\
\hline & AC-ı & 215.0 & 7.314 & & 0.8431 & 79.09 \\
\hline & $A C-\lambda$ & 245.6 & 4.912 & & 0.9315 & 45.27 \\
\hline \multirow{4}{*}{ Sips } & & $N_{T}\left(\mathrm{mg} \cdot{ }^{-1}\right)$ & $a\left(\mathrm{~L} \cdot \mathrm{mg}^{-1}\right)$ & $m$ & $R^{2}$ & $x^{2}$ \\
\hline & AC-K & 460.9 & 1.732 & 0.6913 & 0.9650 & 28.77 \\
\hline & $A C-\iota$ & 327.4 & 3.907 & 1.0 & 0.9808 & 7.412 \\
\hline & $\mathrm{AC}-\lambda$ & 1562.5 & 0.252 & 0.1909 & 0.9315 & 46.07 \\
\hline
\end{tabular}

$q_{L}$ is the monolayer adsorption capacity. $K_{L}$ is the Langmuir isotherm constant. $K_{F}$ is the Freundlich constant. $n$ is a dimensionless constant associated with a heterogeneity factor. $N_{T}$ is the total number of binding sites. $a$ is related to the median binding affinity. $m$ is the heterogeneous index.

A direct comparison between the ACs shows that the maximum adsorption capacity of AC- 1 $(330 \mathrm{mg} / \mathrm{g})$ is lower than for AC- $\mathrm{K}(422 \mathrm{mg} / \mathrm{g})$ or AC- $\lambda(459 \mathrm{mg} / \mathrm{g})$. Among the carbons prepared, the sample AC-ı presented the highest specific surface area $\left(2805 \mathrm{~m}^{2} / \mathrm{g}\right)$ and the lowest carbon content $(72 \mathrm{wt} \%)$, which might indicate that the carbon content on the surface might have a relevant role on the adsorption of ciprofloxacin by these materials.

\subsubsection{Effect of Contact Time and Kinetic Studies}

The time profile of CIP adsorbed onto the ACs was assessed for an initial concentration of $50 \mathrm{mg} / \mathrm{L}$, in order to investigate the kinetics of sorption. It was found that $5 \mathrm{~min}$ of contact time was sufficient to achieve the optimal performance, with CIP removal higher than $99 \%$ (Figure 10). Overall, the adsorption kinetics with these ACs is much faster than others ACs tested in the uptake of CIP in similar conditions and reported in the literature. For example, bamboo-derived ACs tested in identical dose $\left(0.5 \mathrm{mg}_{\mathrm{AC}} / \mathrm{mL}\right)$ and similar initial CIP concentration $(40 \mathrm{mg} / \mathrm{L})$ required several hours to achieve the sorption equilibrium and maximum sorption performance [24].

It is well accepted that the solid-liquid adsorption step involves several steps [60,61]. Initially the sorbate species migrate from the bulk solution to the solid/liquid interface (bulk diffusion). Then the sorbate diffuses across the liquid film surrounding the solid to the surface of the sorbent (film diffusion). Afterwards, the sorbate diffuses in the liquid within the pores (intra-particle diffusion). Finally, the sorbate reacts with the active sites of the sorbents surface through chemical reaction or physical adsorption. The use of kinetic models allows elucidating the adsorption mechanism. The kinetic adsorption data was fitted to two kinetic equations commonly used: the pseudo-first order equation [62] and the pseudo-second order equation (see Supporting Information for model equation model-Table S3) [63]. These models assume that the interaction of the sorbate with the active sites is the rate-limiting step and is of chemical nature [61]. The kinetic parameters and goodness of the fits, obtained by non-linear regression, are reported in Table 4 and the kinetic fittings are shown in Figure 10 and Figure S3 (Supporting Information). Both equations provided a very good fit to the experimental data, with a high coefficient of determination $\left(R^{2}>0.9999\right)$ and low chi-square values $\left(\chi^{2}\right)$. These results indicate that the chemisorption of CIP molecules onto ACs surface is the rate limiting mechanism of CIP adsorption. 

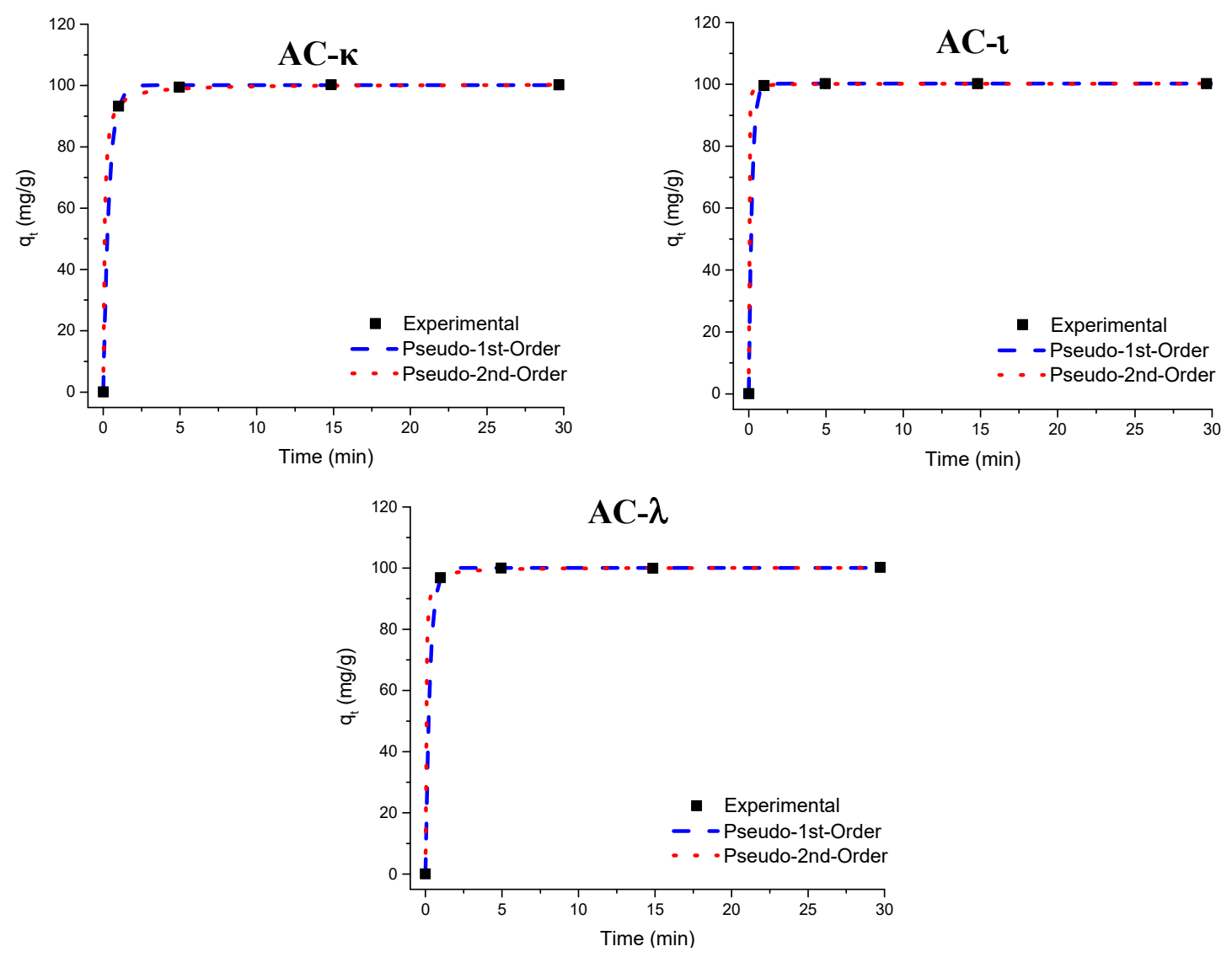

Figure 10. Time profile of CIP adsorption capacity over $30 \mathrm{~min}$ and the corresponding kinetic model fitting using pseudo 1 st and pseudo 2 nd order equations.

Table 4. Kinetic parameters estimated from pseudo 1st order and pseudo 2nd order models and the evaluation of its fittings for an initial CIP concentration of $50 \mathrm{mg} / \mathrm{L}$.

\begin{tabular}{|c|c|c|c|c|c|c|}
\hline \multirow{2}{*}{ Sample } & \multicolumn{3}{|c|}{ Pseudo 1st Order } & \multicolumn{3}{|c|}{ Pseudo 2nd Order } \\
\hline & $R^{2}\left(\chi^{2}\right)$ & $k_{1}\left(\min ^{-1}\right)$ & $q_{e}\left(\mathrm{mg} \cdot \mathrm{g}^{-1}\right)$ & $R^{2}\left(\chi^{2}\right)$ & $k_{2}\left(\mathrm{~g} \cdot \mathrm{mg}^{-1} \cdot \min ^{-1}\right)$ & $q_{e}\left(\mathrm{mg} \cdot \mathrm{g}^{-1}\right)$ \\
\hline AC-k & $\begin{array}{c}0.9999 \\
\left(5.7 \times 10^{-3}\right)\end{array}$ & 2.677 & 100.1 & $\begin{array}{c}0.9999 \\
\left(4.3 \times 10^{-3}\right)\end{array}$ & 0.1309 & 100.5 \\
\hline$A C-\iota$ & $\begin{array}{c}0.9999 \\
\left(7.2 \times 10^{-5}\right)\end{array}$ & 5.009 & 100.2 & $\begin{array}{c}0.9999 \\
\left(1.6 \times 10^{-4}\right)\end{array}$ & 1.459 & 100.2 \\
\hline$A C-\lambda$ & $\begin{array}{c}0.9999 \\
\left(8.6 \times 10^{-4}\right)\end{array}$ & 3.424 & 100.1 & $\begin{array}{c}0.9999 \\
\left(2.6 \times 10^{-3}\right)\end{array}$ & 0.2908 & 100.2 \\
\hline
\end{tabular}

\subsection{Comparison with Other Sorbents}

The measured maximum adsorption capacity was $422 \mathrm{mg} / \mathrm{g}, 330 \mathrm{mg} / \mathrm{g}$ and $459 \mathrm{mg} / \mathrm{g}$ for AC- $\mathrm{\kappa}$, AC- $\iota$ and AC- $\lambda$ activated carbons, respectively. Table 5 shows the CIP adsorption capacity reported for other carbonaceous sorbents, and AC-K and AC- $\lambda$ can be regarded as some of the most effective adsorbents for CIP. The fast adsorption kinetics of these ACs when compared to other materials with high sorption capacity $\left(\mathrm{H}_{3} \mathrm{PO}_{4}\right.$ chemically-activated carbon from bamboo- $\mathrm{AC}$ bamboo $\left./ \mathrm{H}_{3} \mathrm{PO}_{4}\right)$ is also an advantage. The combination of fast CIP uptake and high sorption capacity makes these ACs very attractive for the efficient uptake of CIP from water. 
Table 5. Comparison of the maximum CIP adsorption capacity $\left(q_{\max }\right)$, time to achieve the equilibrium $\left(t_{e}\right)$ and specific surface area $\left(S_{B E T}\right)$ of various carbonaceous adsorbents $\left(\mathrm{T}=25^{\circ} \mathrm{C}\right)$.

\begin{tabular}{cccccc}
\hline Adsorbent & $\boldsymbol{q}_{\max }(\mathbf{m g} / \mathbf{g})$ & $\boldsymbol{S}_{\boldsymbol{B E T}}\left(\mathbf{m}_{\mathbf{2}} / \mathbf{g}\right)$ & $\boldsymbol{t}_{\boldsymbol{e}}$ & $\mathbf{p H}$ & Reference \\
\hline $\mathrm{AC}-\mathrm{k}$ & 422 & 2346 & $5 \mathrm{~min}$ & 6 & (this work) \\
$\mathrm{AC}-\mathrm{\iota}$ & 330 & 2805 & $5 \mathrm{~min}$ & 6 & (this work) \\
$\mathrm{AC}-\lambda$ & 459 & 2516 & $5 \mathrm{~min}$ & 6 & (this work) \\
Powder activated carbon & 109 & 1075 & $>2 \mathrm{~h}$ & 6.2 & {$[64]$} \\
$\mathrm{AC}_{\text {bamboo }} / \mathrm{H}_{3} \mathrm{PO}_{4}$ & 613.0 & 2237 & $>2 \mathrm{~h}$ & 6 & {$[24]$} \\
$\mathrm{AC}_{\text {peach-stones }} / \mathrm{H}_{3} \mathrm{PO}_{4}$ & 263.7 & 1521 & $>4 \mathrm{~h}$ & 6.5 & {$[22]$} \\
$\mathrm{AC}_{\text {wood }} / \mathrm{H}_{3} \mathrm{PO}_{4}$ & 231.0 & 1237 & $20 \mathrm{~h}$ & 5 & {$[20]$} \\
$\mathrm{AC}_{\text {albizia-seed }} / \mathrm{Microwave}_{\text {Multiwalled Carbon Nanotubes }}$ & 131 & 1824 & $>2 \mathrm{~h}$ & 9 & {$[65]$} \\
$\mathrm{AC}$ palm leaflets & 206 & 382 & $>1 \mathrm{~h}$ & 4 & {$[21]$} \\
Magnetic Carbon Nanocomposite & 116.3 & 24.4 & $48 \mathrm{~h}$ & 6 & {$[13]$} \\
\hline
\end{tabular}

As for pilot studies, a study worth mentioning has investigated the efficacy of a fluidized activated carbon pilot as tertiary treatment to remove a wide range of pollutants from wastewater treatment plant effluents. While many pollutants are shown to be removed, there was an average $87 \%$ removal for ciprofloxacin [66], which is a favorable indicator of the potential of the ACs developed herein for CIP removal in continuous flow conditions.

\section{Conclusions}

Hydrochars and porous-activated carbons prepared from three distinct carrageenan polysaccharides, $\mathrm{k}$-, $\mathrm{l}$ - and $\lambda$-carrageenan, have been reported here. The ability of these materials to uptake the antibiotic ciprofloxacin from aqueous solutions was investigated in several operational conditions. The ACs prepared from $\mathrm{k}$ - and $\lambda$-carrageenan have shown a greater adsorption capacity towards ciprofloxacin, when compared to most of the carbonaceous sorbents previously reported, which place these sorbents among the most efficient for this emergent pollutant in the tested conditions. Moreover, the adsorption was very fast, achieving the equilibrium conditions in approximately $5 \mathrm{~min}$. Such good adsorptive performance could be attributed to a combined effect of high specific surface area (above $2300 \mathrm{~m}^{2} / \mathrm{g}$ ), high microporosity (near $1 \mathrm{~cm}^{3} / \mathrm{g}$ ) and high carbon content. The kinetics and equilibrium modelling analysis indicate that the chemisorption of CIP molecules onto ACs surface is the rate limiting step and that equilibrium sorption is well described by Sips isotherm. These findings demonstrate the potential of ACs prepared from carrageenan polymers as adsorbents for removal of antibiotic pollutants from water. With the aim of evaluating these sorbents in realistic conditions, subsequent studies are planned using real water samples contaminated with ciprofloxacin. The study of the regeneration and reuse of the ACs should also be considered due to economic reasons. Based on previous findings, several treatments could be tested in the regeneration of ACs loaded with ciprofloxacin [13,67-72]. An alternative fate of spent sorbents that takes advantage of the potential of ciprofloxacin as a corrosion inhibitor [73] is their use as a resource in the preparation of other materials, following a circular economy approach.

Supplementary Materials: The following are available online at http:/ / www.mdpi.com/2079-4991/8/12/1004/ s1, Figure S1: Powder XRD pattern of HC and AC materials, Table S1: Selected infrared bands $\left(\mathrm{cm}^{-1}\right)$ for the materials and respective assignments, Figure S2: Speciation of CIP, Table S2: Isotherm models and parameters, Table S3: Kinetic models and parameters. Figure S3: Time profile of CIP adsorption capacity over 24h and corresponding kinetic model fitting.

Author Contributions: A.L.D.-d.-S. and T.T. conceived the topic and supervised the experimental work. J.N. and A.L.D.-d.-S. outlined the manuscript and mainly wrote it. S.F. assisted in the RAMAN spectroscopy studies of the carbon materials. S.M. assisted in the carbon activation procedures. M.A. contributed to the drafting of the manuscript. All the authors contributed to the discussion and reviewed the manuscript.

Funding: This research was funded by Portuguese Foundation for Science and Technology—FCT (FCT Ref. UID/CTM/50011/2013) and the IF-2014 FCT investigator Programme. 
Acknowledgments: This work was developed within the scope of the project CICECO-Aveiro Institute of Materials, POCI-01-0145-FEDER-007679 (FCT Ref. UID/CTM/50011/2013), and when appropriate co-financed by European Regional Development Fund (FEDER) under the PT2020 Partnership Agreement. The authors thank the RNME (National Electronic Microscopy Network) for microscopy facilities. A.L.D.-d.-S. acknowledges Portuguese Foundation for Science and Technology (FCT) for the IF-2014 FCT Investigator Programme and funding from the project IF/00405/2014. S.F. thanks FCT for the postdoctoral grant (SFRH/BPD/93547/2013).

Conflicts of Interest: The authors declare no conflict of interest.

\section{References}

1. Sousa, J.C.G.; Ribeiro, A.R.; Barbosa, M.O.; Pereira, M.F.R.; Silva, A.M.T. A review on environmental monitoring of water organic pollutants identified by EU guidelines. J. Hazard. Mater. 2018, 344, 146-162. [CrossRef]

2. Radović, T.; Grujić, S.; Petković, A.; Dimkić, M.; Laušević, M. Determination of pharmaceuticals and pesticides in river sediments and corresponding surface and ground water in the Danube River and tributaries in Serbia. Environ. Monit. Assess. 2015, 187. [CrossRef] [PubMed]

3. Gavrilescu, M.; Demnerová, K.; Aamand, J.; Agathos, S.; Fava, F. Emerging pollutants in the environment: Present and future challenges in biomonitoring, ecological risks and bioremediation. N. Biotechnol. 2015, 32, 147-156. [CrossRef] [PubMed]

4. Windsor, F.M.; Ormerod, S.J.; Tyler, C.R. Endocrine disruption in aquatic systems: up-scaling research to address ecological consequences. Biol. Rev. 2018, 93, 626-641. [CrossRef]

5. Deblonde, T.; Cossu-Leguille, C.; Hartemann, P. Emerging pollutants in wastewater: A review of the literature. Int. J. Hyg. Environ. Health 2011, 214, 442-448. [CrossRef] [PubMed]

6. Paíga, P.; Correia, M.; Fernandes, M.J.; Silva, A.; Carvalho, M.; Vieira, J.; Jorge, S.; Silva, J.G.; Freire, C.; Delerue-Matos, C. Assessment of 83 pharmaceuticals in WWTP influent and effluent samples by UHPLC-MS/MS: Hourly variation. Sci. Total Environ. 2019, 648, 582-600. [CrossRef]

7. Khattab, F.; Salem, H.; Riad, S.; Elbalkiny, H. Determination of fluoroquinolone antibiotics in industrial wastewater by high-pressure liquid chromatography and thin-layer chromatography-densitometric methods. J. Planar Chromatogr. Mod. TLC 2014, 27, 287-293. [CrossRef]

8. Pereira, A.M.P.T.; Silva, L.J.G.; Lino, C.M.; Meisel, L.M.; Pena, A. Assessing environmental risk of pharmaceuticals in Portugal: An approach for the selection of the Portuguese monitoring stations in line with Directive 2013/39/EU. Chemosphere 2016, 144, 2507-2515. [CrossRef]

9. Ahmadzadeh, S.; Asadipour, A.; Pournamdari, M.; Behnam, B.; Reza Rahimi, H.; Dolatabadi, M. Removal of ciprofloxacin from hospital wastewater using electrocoagulation technique by aluminum electrode: Optimization and modelling through response surface methodology. Process Saf. Environ. Prot. 2017, 109. [CrossRef]

10. Rehman, M.S.U.; Rashid, N.; Ashfaq, M.; Saif, A.; Ahmad, N.; Han, J.I. Global risk of pharmaceutical contamination from highly populated developing countries. Chemosphere 2015, 138, 1045-1055. [CrossRef]

11. Riaz, L.; Mahmood, T.; Khalid, A.; Rashid, A.; Ahmed Siddique, M.B.; Kamal, A.; Coyne, M.S. Fluoroquinolones (FQs) in the environment: A review on their abundance, sorption and toxicity in soil. Chemosphere 2018, 191, 704-720. [CrossRef] [PubMed]

12. Hernández, F.; Calısto-Ulloa, N.; Gómez-Fuentes, C.M.; Gómez, J.F.; González-Rocha, G.; Bello-Toledo, H.; Botero-Coy, A.M.; Bo1x, C.; Ibáñez, M.; Montory, M. Occurrence of antibiotics and bacterial resistance in wastewater and sea water from the Antarctic. J. Hazard. Mater. 2018, 447-456, in press. [CrossRef]

13. El-Shafey, E.S.I.; Al-Lawati, H.; Al-Sumri, A.S. Ciprofloxacin adsorption from aqueous solution onto chemically prepared carbon from date palm leaflets. J. Environ. Sci. 2012, 24, 1579-1586. [CrossRef]

14. Krzeminski, P.; Tomei, M.C.; Karaolia, P.; Langenhoff, A.; Almeida, C.M.R.; Felis, E.; Gritten, F.; Andersen, H.R.; Fernandes, T.; Manaia, C.M.; et al. Performance of secondary wastewater treatment methods for the removal of contaminants of emerging concern implicated in crop uptake and antibiotic resistance spread: A review. Sci. Total Environ. 2019, 648, 1052-1081. [CrossRef] [PubMed]

15. Mondal, S.K.; Saha, A.K.; Sinha, A. Removal of ciprofloxacin using modified advanced oxidation processes: Kinetics, pathways and process optimization. J. Clean. Prod. 2018, 171, 1203-1214. [CrossRef]

16. Li, W.; Guo, C.; Su, B.; Xu, J. Photodegradation of four fluoroquinolone compounds by titanium dioxide under simulated solar light irradiation. J. Chem. Technol. Biotechnol. 2012, 87, 643-650. [CrossRef] 
17. Stadlmair, L.F.; Letzel, T.; Drewes, J.E.; Grassmann, J. Enzymes in removal of pharmaceuticals from wastewater: A critical review of challenges, applications and screening methods for their selection. Chemosphere 2018, 205, 649-661. [CrossRef]

18. Yu, F.; Li, Y.; Han, S.; Ma, J. Adsorptive removal of antibiotics from aqueous solution using carbon materials. Chemosphere 2016, 153, 365-385. [CrossRef]

19. De Andrade, J.R.; Oliveira, M.F.; Da Silva, M.G.C.; Vieira, M.G.A. Adsorption of Pharmaceuticals from Water and Wastewater Using Nonconventional Low-Cost Materials: A Review. Ind. Eng. Chem. Res. 2018, 57, 3103-3127. [CrossRef]

20. Carabineiro, S.A.C.; Thavorn-Amornsri, T.; Pereira, M.F.R.; Serp, P.; Figueiredo, J.L. Comparison between activated carbon, carbon xerogel and carbon nanotubes for the adsorption of the antibiotic ciprofloxacin. Catal. Today 2012, 186, 29-34. [CrossRef]

21. Yu, F.; Sun, S.; Han, S.; Zheng, J.; Ma, J. Adsorption removal of ciprofloxacin by multi-walled carbon nanotubes with different oxygen contents from aqueous solutions. Chem. Eng. J. 2016, 285, 588-595. [CrossRef]

22. Álvarez-Torrellas, S.; Peres, J.A.; Gil-Álvarez, V.; Ovejero, G.; García, J. Effective adsorption of non-biodegradable pharmaceuticals from hospital wastewater with different carbon materials. Chem. Eng. J. 2017, 320, 319-329. [CrossRef]

23. Shi, S.; Fan, Y.; Huang, Y. Facile low temperature hydrothermal synthesis of magnetic mesoporous carbon nanocomposite for adsorption removal of ciprofloxacin antibiotics. Ind. Eng. Chem. Res. 2013, 52, 2604-2612. [CrossRef]

24. Wang, Y.X.; Ngo, H.H.; Guo, W.S. Preparation of a specific bamboo based activated carbon and its application for ciprofloxacin removal. Sci. Total Environ. 2015, 533, 32-39. [CrossRef] [PubMed]

25. Zhang, B.; Han, X.; Gu, P.; Fang, S.; Bai, J. Response surface methodology approach for optimization of ciprofloxacin adsorption using activated carbon derived from the residue of desilicated rice husk. J. Mol. Liq. 2017, 238, 316-325. [CrossRef]

26. Mansour, F.; Al-Hindi, M.; Yahfoufi, R.; Ayoub, G.M.; Ahmad, M.N. The use of activated carbon for the removal of pharmaceuticals from aqueous solutions: a review. Rev. Environ. Sci. Biotechnol. 2017, 17, 1-37. [CrossRef]

27. Correa, C.R.; Kruse, A. Biobased functional carbon materials: Production, characterization, and applications-A review. Materials 2018, 11. [CrossRef]

28. Yang, Y.; Cui, J.; Zheng, M.; Hu, C.; Tan, S.; Xiao, Y.; Yang, Q.; Liu, Y. One-step synthesis of amino-functionalized fluorescent carbon nanoparticles by hydrothermal carbonization of chitosan. Chem. Commun. 2012, 48, 380-382. [CrossRef]

29. Marrakchi, F.; Ahmed, M.J.; Khanday, W.A.; Asif, M.; Hameed, B.H. Mesoporous-activated carbon prepared from chitosan flakes via single-step sodium hydroxide activation for the adsorption of methylene blue. Int. J. Biol. Macromol. 2017, 98, 233-239. [CrossRef]

30. Guan, J.; Li, L.; Mao, S. Chapter 15-Applications of Carrageenan in Advanced Drug Delivery; Venkatesan, J., Anil, S., Kim, S.-K.B.T.-S.P., Eds.; Elsevier: Amsterdam, The Netherlands, 2017; pp. 283-303, ISBN 978-0-12-809816-5.

31. Stephen, A.M.; Phillips, G.O.; Williams, P.A. Food Polysaccharides and Their Applications, 2nd ed.; CRC Press Taylor \& Francis Group: Boca Raton, FL, USA, 2006; ISBN 9780824759223.

32. Nanaki, S.G.; Kyzas, G.Z.; Tzereme, A.; Papageorgiou, M.; Kostoglou, M.; Bikiaris, D.N.; Lambropoulou, D.A. Synthesis and characterization of modified carrageenan microparticles for the removal of pharmaceuticals from aqueous solutions. Colloids Surf. B Biointerfaces 2015, 127, 256-265. [CrossRef]

33. Soares, S.F.; Simões, T.R.; António, M.; Trindade, T.; Daniel-da-Silva, A.L. Hybrid nanoadsorbents for the magnetically assisted removal of metoprolol from water. Chem. Eng. J. 2016, 302, 560-569. [CrossRef]

34. Fernandes, T.; Soares, S.; Trindade, T.; Daniel-da-Silva, A. Magnetic Hybrid Nanosorbents for the Uptake of Paraquat from Water. Nanomaterials 2017, 7, 68. [CrossRef] [PubMed]

35. Papageorgiou, M.; Nanaki, S.G.; Kyzas, G.Z.; Koulouktsi, C.; Bikiaris, D.N.; Lambropoulou, D.A. Novel isocyanate-modified carrageenan polymer materials: Preparation, characterization and application adsorbent materials of pharmaceuticals. Polymers 2017, 9. [CrossRef]

36. Raymundo-Piñero, E.; Cadek, M.; Béguin, F. Tuning carbon materials for supercapacitors by direct pyrolysis of seaweeds. Adv. Funct. Mater. 2009, 19, 1032-1039. [CrossRef] 
37. Fan, Y.; Yang, X.; Zhu, B.; Liu, P.F.; Lu, H.T. Micro-mesoporous carbon spheres derived from carrageenan as electrode material for supercapacitors. J. Power Sources 2014, 268, 584-590. [CrossRef]

38. ISO (International Organisation for Standardisation). Determination of the Specific Surface Area of Solids by Gas Adsorption-BET Method (ISO 9277); ISO: Geneva, Switzerland, 2010.

39. Gregg, S.J.; Sing, K.S.W. Adsorption, Surface Area and Porosity, 2nd ed.; Academic Press: London, UK, 1982.

40. Dubinin, M.M. Fundamentals of the theory of adsorption in micropores of carbon adsorbents: Characteristics of their adsorption properties and microporous structures. Carbon N. Y. 1989, 27, 457-467. [CrossRef]

41. Romanos, J.; Beckner, M.; Rash, T.; Firlej, L.; Kuchta, B.; Yu, P.; Suppes, G.; Wexler, C.; Pfeifer, P. Nanospace engineering of $\mathrm{KOH}$ activated carbon. Nanotechnology 2012, 23. [CrossRef]

42. Chen, W.; Rakhi, R.B.; Hedhili, M.N.; Alshareef, H.N. Shape-controlled porous nanocarbons for high performance supercapacitors. J. Mater. Chem. A 2014, 2, 5236-5243. [CrossRef]

43. Zhu, Y.; Murali, S.; Stoller, M.D.; Ganesh, K.J.; Cai, W.; Ferreira, P.J.; Pirkle, A.; Wallace, R.M.; Cychosz, K.A.; Thommes, M.; et al. Carbon-Based Supercapacitors Produced by Activation of Graphene. Science 2011, 332, 1537-1541. [CrossRef]

44. Rivera-Utrilla, J.; Sánchez-Polo, M.; Gómez-Serrano, V.; Álvarez, P.M.; Alvim-Ferraz, M.C.M.; Dias, J.M. Activated carbon modifications to enhance its water treatment applications. An overview. J. Hazard. Mater. 2011, 187, 1-23. [CrossRef]

45. Thommes, M.; Kaneko, K.; Neimark, A.V.; Olivier, J.P.; Rodriguez-Reinoso, F.; Rouquerol, J.; Sing, K.S.W. Physisorption of gases, with special reference to the evaluation of surface area and pore size distribution (IUPAC Technical Report). Pure Appl. Chem. 2015, 87, 1051-1069. [CrossRef]

46. Dresselhaus, M.S.; Jorio, A.; Hofmann, M.; Dresselhaus, G.; Saito, R. Perspectives on Carbon Nanotubes and Graphene Raman Spectroscopy. Nano Lett. 2010, 10, 751-758. [CrossRef] [PubMed]

47. Lozano-Castelló, D.; Lillo-Ródenas, M.A.; Cazorla-Amorós, D.; Linares-Solano, A. Preparation of activated carbons from Spanish anthracite - I. Activation by KOH. Carbon N. Y. 2001, 39, 741-749. [CrossRef]

48. Biniak, S. The characterization of activated carbons with oxygen and nitrogen surface groups. Carbon 1997, 35, 1799-1810. [CrossRef]

49. Tekin, K.; Karagöz, S.; Bektaş, S. A review of hydrothermal biomass processing. Renew. Sustain. Energy Rev. 2014, 40, 673-687. [CrossRef]

50. Bedin, K.C.; Cazetta, A.L.; Souza, I.P.A.F.; Pezoti, O.; Souza, L.S.; Souza, P.S.C.; Yokoyama, J.T.C.; Almeida, V.C. Porosity enhancement of spherical activated carbon: Influence and optimization of hydrothermal synthesis conditions using response surface methodology. J. Environ. Chem. Eng. 2018, 6, 991-999. [CrossRef]

51. Carmosini, N.; Lee, L.S. Chemosphere Ciprofloxacin sorption by dissolved organic carbon from reference and bio-waste materials. Chemosphere 2009, 77, 813-820. [CrossRef] [PubMed]

52. Drakopoulos, A.I.; Ioannou, P.C. Spectrofluorimetric study of the acid-base equilibria and complexation behavior of the fluoroquinolone antibiotics ofloxacin, norfloxacin, ciprofloxacin and pefloxacin in aqueous solution. Anal. Chim. Acta 1997, 354, 197-204. [CrossRef]

53. Zhao, Q.; Zhang, S.; Zhang, X.; Lei, L.; Ma, W.; Ma, C.; Song, L.; Chen, J.; Pan, B.; Xing, B. Cation-Pi Interaction: A Key Force for Sorption of Fluoroquinolone Antibiotics on Pyrogenic Carbonaceous Materials. Environ. Sci. Technol. 2017, 51, 13659-13667. [CrossRef]

54. Ma, J.; Yang, M.; Yu, F.; Zheng, J. Water-enhanced Removal of Ciprofloxacin from Water by Porous Graphene Hydrogel. Sci. Rep. 2015, 5, 13578. [CrossRef]

55. Langmuir, I. The adsorption of gases on plance surfaces of glass, mica and platnium. J. Am. Chem. Soc. 1918, 40,1361-1403. [CrossRef]

56. Freundlich, H. Concerning Adsorption in Solutions. Zeitschrift fur physikalische chemie-stochiometrie und verwandtschaftslehre. Phys. Chem. 1906, 57, 385-470.

57. Sips, R. On the structure of a catalyst surface. J. Chem. Phys. 1948, 16, 490-495. [CrossRef]

58. Umpleby, R.J.; Baxter, S.C.; Chen, Y.; Shah, R.N.; Shimizu, K.D. Characterization of Molecularly Imprinted Polymers with the Langmuir-Freundlich Isotherm. Anal. Chem. 2001, 73, 4584-4591. [CrossRef] [PubMed]

59. Ho, Y.S.; Porter, J.F.; McKay, G. Equilibrium isotherm studies for the sorption of divalent metal ions onto peat: Copper, nickel and lead single component systems. Water. Air. Soil Pollut. 2002, 141, 1-33. [CrossRef] 
60. McKay, G.; Allen, S.J.; McConvey, I.F.; Walters, J.H.R. External mass transfer and homogeneous solid-phase diffusion effects during the adsorption of dyestuffs. Ind. Eng. Chem. Process Des. Dev. 1984, 23, 221-226. [CrossRef]

61. Grégorio, C.; Lichtfouse, E.D.; Wilson, L.; Morin-Crini, N. Adsorption-Oriented Processes Using Conventional and Non-conventional Adsorbents for Wastewater Treatment. In Green Adsorbents for Pollutant Removal; Springer Nature: Basingstoke, UK, 2018; pp. 23-71, ISBN 978-3-319-92110-5.

62. Lagergren, S. Zur Theorie der Sogenannten Adsorption Gelöster Stoffe, Kungliga Svenska Vetenskapsakademiens. Handlingar 1989, 24, 1-39.

63. Ho, Y.S.; McKay, G. Pseudo-second order model for sorption processes. Process Biochem. 1999, 34, 451-465. [CrossRef]

64. Li, X.; Chen, S.; Fan, X.; Quan, X.; Tan, F.; Zhang, Y.; Gao, J. Adsorption of ciprofloxacin, bisphenol and 2-chlorophenol on electrospun carbon nanofibers: In comparison with powder activated carbon. J. Colloid Interface Sci. 2015, 447, 120-127. [CrossRef]

65. Ahmed, M.J.; Theydan, S.K. Fluoroquinolones antibiotics adsorption onto microporous activated carbon from lignocellulosic biomass by microwave pyrolysis. J. Taiwan Inst. Chem. Eng. 2014, 45, 219-226. [CrossRef]

66. Mailler, R.; Gasperi, J.; Coquet, Y.; Deshayes, S.; Zedek, S. Study of a large scale powdered activated carbon pilot: Removals of a wide range of emerging and priority micropollutants from wastewater treatment plant effluents. Water Res. 2015, 72, 315-330. [CrossRef]

67. Snyder, S.A.; Adham, S.; Redding, A.M.; Cannon, F.S.; Decarolis, J.; Oppenheimer, J.; Wert, E.C.; Yoon, Y. Role of membranes and activated carbon in the removal of endocrine disruptors and pharmaceuticals. Desalination 2007, 202, 156-181. [CrossRef]

68. Purkait, M.K.; Maiti, A.; DasGupta, S.; De, S. Removal of congo red using activated carbon and its regeneration. J. Hazard. Mater. 2007, 145, 287-295. [CrossRef] [PubMed]

69. Matatov-Meytal, Y.I.; Sheintuch, M. Abatement of Pollutants by Adsorption and Oxidative Catalytic Regeneration. Ind. Eng. Chem. Res. 1997, 36, 4374-4380. [CrossRef]

70. Kim, J.H.; Ryu, Y.K.; Haam, S.; Lee, C.H.; Kim, W.S. Adsorption and steam regeneration of n-hexane, MEK, and toluene on activated carbon fiber. Sep. Sci. Technol. 2001, 36, 263-281. [CrossRef]

71. Hassanzadeh, S.; Aminlashgari, N.; Hakkarainen, M. Microwave-assisted recycling of waste paper to green platform chemicals and carbon nanospheres. ACS Sustain. Chem. Eng. 2014, 3, 177-185. [CrossRef]

72. Fang, C.S.; Lai, P.M.C. Microwave Regeneration of Spent Powder Activated Carbon. Chem. Eng. Commun. 1996, 147, 17-27. [CrossRef]

73. Eddy, N.O.; Stoyanov, S.R.; Ebenso, E.E. Fluoroquinolones as corrosion inhibitors for mild steel in acidic medium; Experimental and theoretical studies. Int. J. Electrochem. Sci. 2010, 5, 1127-1150. 